\title{
ADLİ OLAYLARDA BÖCEKLERDEN NASIL YARARLANIRIZ?
}

\author{
Dr. H. Nihal AÇIKGÖZ \\ Prof. Dr. I. Hamit HANCI" \\ Prof. Dr. Gürsel ÇETIN"**
}

\section{ÖZET}

Ölüm ve ölüm sonrası bulgularla adli tıp uygulamalarında ölüm zamanı tayininde çok çeşitli kriterler ve yöntemler kullanılmakla birlikte bu yöntemlerin hiç biri tam güvenilir sonuçlar vermemektedir. Ancak adli olaylarda, böceklerden yararlanılarak, ölümün gerçekleştiği yerin ve ölüm zamanının belirlenmesi çalışmaları, şiddete dayalı bir çok olayın çözülmesinde adli tıp uzmanlarına yol göstericidir. Zengin bir biyolojik çevreye sahip olan ülkemizde, adli entomolojinin, adli tıp uygulamalarında kullanılmasının çok yararlı olacağı kanısındayız.

Çürüme (Dekompozisyon) : Çürüme ya da kokuşma ölümden sonra cesedin çürüyüp dağılarak yok olmasıdır $(3,5,6)$.

Biyolojik varlıklar, öldükten sonra çürümek ve ekolojik sisteme katılmak durumundadır. Ölüm sonrası değişikliklerin sona ermesi yıllar, yüzyıllar; hatta binlerce yıl alabilir. Yalnızca iskeletin fosilleşmesi moleküler yapı dışında kalıcıdır.

Dekompozisyon, doğanın ekolojik dengesi ve canlılığın devamı için de bir zorunluluktur. Organik yapı taşlarından oluşan insan vüicudu, ölümden sonraki olumsuz deģişimlerin sonuncusu olan dekompozisyon ile kendisini teşkil eden organik bileşiklerin temel basit elemanlarına ayrılarak yok olurken, doğadaki elementlerin değişim çemberindeki yerini de almış olur. Karmaşık ve gelişmiş organik bileşiklerin kendilerini oluşturan basit

- Ankara Üniversitesi Adli Tıp Enstitüsü

"Ankara Universitesi Tip Fak. Adlj Tip A.D

"** İstanbul Universitesi Cerrahpaşa Tıp Fak. Adli Tıp A.D 
elemanlara ayrılması, bakterilerin ürettikleri proteolitik ve diğer enzimlerin etkisi ile gerçekleşir. Bu enzimlerin tesiri ile dokular gaz, sıvı ve tuzlara ayrilarak yok olurlar.

Dekompozisyon olayı, otoliz ve piitrefaksiyon (çürüme) olmak üzere iki aşamayı kapsar. Otolizde, dokuların hücre içi enzimler yolu ile aseptik kimyasal yoldan bozulması söz konusudur. Pütrefaksiyonda ise, dokuların ve organların esas ofarak bakterilere bağlı olarak yapıları bozular. Dekompozisyonun ağ

\section{Çürümeye Etki Eden Faktörler}

Çürümenin başlama ve ilerleme huzında büyük deģişiklikler olmakla birlikte, canl, etkenler, kimyasal olaylat, fiziksel etkenler çürümenin başlıca faktörleridir.

\section{Canls Etkenler}

Çürümeyi gerçekleştiren en büyiik etken, viicudun normal florasmı teşkil eden bakteriler ile varsa patojen bakterilerdir. Canl iken viicutta bulunan bakteriler, ölümden sonra carlılığını yitiren vücudun, bakterilerin büyümesi için mükemmel bir ortam olması nedeniyle, çoğalarak dokuları istila eder. Ólümden sonra vücuttaki bakterilerin sistematik analizini yapan Burn ölümden sonra dokularda bulunan bakterileri sik ve seyrek olarak rastlanan bakteriler olmak üzere iki gruba ayırmıştır Birinci grupta Clostridjum Welchij gibi sporlu anaesobik bakteriler, koliform bakteriler. mikrokoklar, difteroid basiller, proteuslar bulunur. Bilindiği gibi bu bakteriler, sindirim kanalı ve solunum sisteminde bulunmaktadı. Olümden sonra faaljyetlerine devam ederek savunmayı bozup dokuları istila ederler. İkinci grup bakteriler ise patojen ve patojen olmayan geniş bir grubu kapsar. Cesetten patojen bir bakteri izole edildiğinde, o organdaki bir hastalığın nedeni olarak değerlendirilmeleri normaldir. Patojen bakterilerin varlı⿳̆ çürümeyi hızlandırır. Septik düşüklere bağlı ölümlerle gazlı gangrende çürüme oldukça hızlı gelişir. Akuı enfeksiyonlar özellikle pulmoner enfeksiyon ve sepsislerde çürüme çok hızl seyreder. Viicudun jçerdiği bakteri sayısı da çok önemlidir. Oldukı̧a az sayıda bakteri içeren yeni doğan bedeni geç çürür.

Diş ortamda uzun süre kalan cesetlerde ise özellikle insectlerin rolü ön plana çıar. Bunun yanında cesedin buiunduğu ortama bağh olarak etoburlar. kemiriciler. balıklar ve diğer canlılar da cesede saldırarak cesedin dekompozisyonuna katkıda bulunur. Çürüyen cesetler farklı canlı türleri için geçici, değ ģşen bir besin kaynağı oluşturur (6). 
Açıkta kalan cesetlere gelince, bunları donuz, kurt, köpek, tilki, çakal, surtlan gibi hayvanlar didiklemek ve parçalamak suretiyle tahrip ederler. Bunların yanında farelerin faaliyeti çok önemlidir. Fareler, yanak, ökçe, kulak kepçesi ve saçlı deri ile ayak gibi vücudun yağlı ve kıkırdaklı kısım!larını kısa bir zamanda kemirerek çürümeye yardımcı olurlar.

Kuşlar içinde kartallar, akbabalar, çaylaklar, kargalar; denizde veya deniz kenarında bulunan cesetlerde de martılar, albatroslar, balıklar vs. deniz hayvanları pek çok tahribat yaparlar. Fakat bütün bu tahribat sineklerin faaliyetinin yanında hiç kalır. Gerçekten de sıcak mevsimlerde ölümü takip eden ilk anda, hatta bazen agoni devresinde bile haşereler, özellikle sinekler, yumurtaları cesedin burun deliklerine, dudak commisura'sına, kulak meatus'üne, göz pınarlarma ve anüse bırakırlar. Bu yumurtalar beyaz renkte, adeta sủttozu, talaş tozu, kaşar peyniri tozu manzarasındadırlar. Eger ceset gömültneyip açık havada kalırsa, diğer haşereler birbirini takip ederek gelirler ve ceset tamamen mahvoluncaya kadar işlerine devam ederler. Bu yüzden sıcak mevsimlerde açıkta bırakılan cesetleri, bu haşereler çok kisa zamanda tahrip ederler. Ünlü sistematikçi Linne, "Üç sinek bir arslandan daha çabuk cesedi tahrip eder" demektedir.

Cesede düzenli olarak gelen insect grupları, beslenmelerine elverişli olan maddeleri yiyip gider ve yerlerini kendilerinden sonra gelecek diğer gruba terk ederler $(5,11)$.

Cesetlere musallat olan bu insectlerin düzenli bir stra takip ettiklerini 1850 ytlında ilk defa Bergere söylemiş ve bunların ceset üzerindeki üremelerini inceleyerek ölüm zamanını mümkün mertebe tayine çalışmıştır. Bu çalışmaya uzun bir süre ara verildikten sonra $1878^{\prime}$ de Brouardel ile Megnin beraberce çalışarak elde ettikleri sonuçları adli tıbba uygulamaya başlamışlardır.

Megnin 15 senelik bir çalışmadan sonra ceset üzerinde yaşayan insectleri smoflara ayırmiş ve bu ölüm işçilerinin birbirlerini takip edişinin prensiplerini ortaya koymuştur. Bu prensipler sayesinde ölümün tarihi hakkında bazı bilgiler elde etmek mümkün olmaktadır. Bunun için de bu insect çeşitlerinin her birinin larva ve erişkinlerini incelemek gerekir. Ölï böceklerin incelenmesi Adli Tıp alanmnda çok önemlidir. Bu inceleme bize, canlı varlıklara ait olan bileşik maddelerin parazit hayvanlar tarafından nasıl tam bir şekilde değiştirilip yok edildiğini gösterir. Ôyle ki bu ölï iş̧̧ileri, işlerini bitirdikleri zaman artık kadavradan, bu haşerelerin ve acarinlerin ifrazatından ibaret olan bir toz kitlesinden başka bir şey kalmaz (5). 


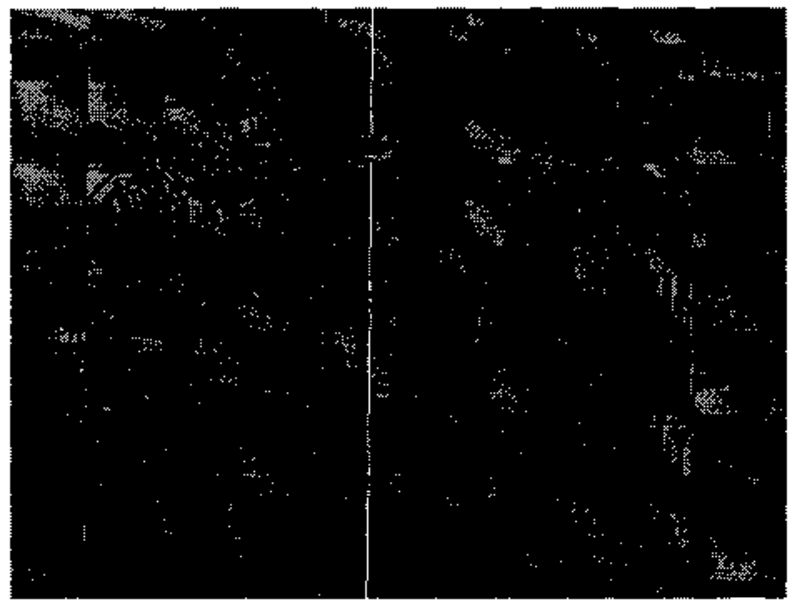

www.dpo.uab.edu/jwells/FBL.html

\section{Adli Entomolojinin Önemi}

Adli entomoloji arthropod bilimdalı ile adli bilimlerin birbirini etkilediği geniş bir bilim dalıdır. Bu bilim dalı önceleri "medicolegal entomology" yada "forensic medical entomology" diye anılırken, çoğunluğu şiddet suçları olmak üzere bir çok suçun çözümünde arthropodlar delil olarak kullanıldı̆̆ından, artık günümüzde yaygın olarak "medicocriminal entomology" olarak anılmaya başlanınıştır (1). Adli Entomolog tarafından toplanan. saklanan ve analiz edilen böcekler, ölüm zamanı ve yeri için delil olarak kullanılır. Böcek bilimciler, adli tıp araştırma takımının üyeleridirler.

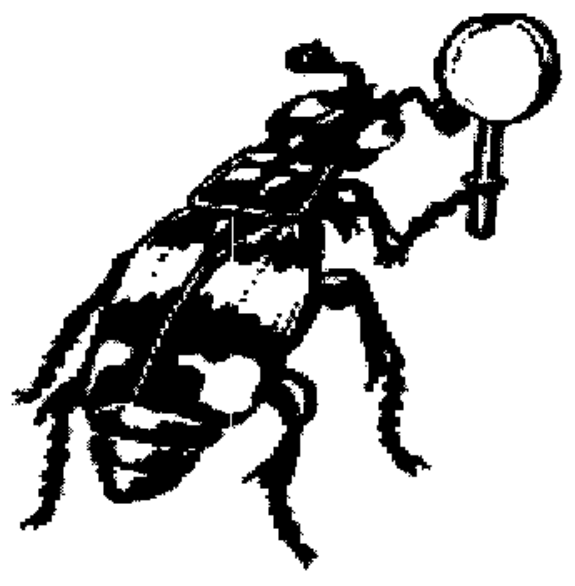


Bütün böceklerin ihtiyaçlarına uygun yer ve zamanda yerleşecekleri bir oyuk vardır (10). Pek çok yıldır göz, burun ve diğer deliklerde ve ceset izerindeki yaraların olduğu yerlerde bulunan kurtcuklar ölünün tiksindirici ŏgesi olarak düşünülürdü. Cesetler, genellikle yıkandıktan sonra otopsi masasına konurdu. Adli bilimlerde balistik, ateşli silah muayenesi, ısırık izleri, barut tozu kalıntısı, sıçramış kan analizi ve suç biliminin diğer elemanları çalışılır, geliştirilir, ölüm yeri ile birlikte böcekler ihmal edilirdi. Zamanla bazı bilim adamları adli entomolojiyi araştırdılar, bu alanda araştırma yapmanın gizli ve büyüleyici olduğunu düşündüler. Adli entomoloji, adli sistemde suç araştırmalarında hem yaşayan (katil) hem de öleni incelemek için kullanılmakla beraber, sivil yanı da vardır. Depolanan yiyeceklerde kontaminasyonları da (bulaşma) araştırır (4).

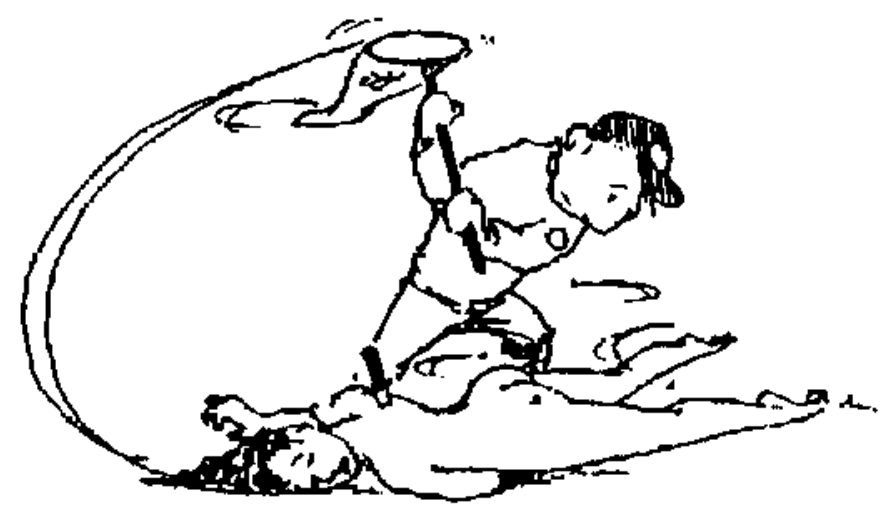

www.uio.no/ mostarke/forens_entçheml

Doğanın ekolojik dengesinde, leşlerin çürüme ve dağılması (decompozisyonu) böcek aktivitesi ile gerçekleştirilir. Calliphoridae (uçan sinek), Sarcophagidae (et sineği) ve Muscidae (ev sineği) familyasına ait olan Dipterler çürümenin ilk basamağında görüllürler. Dermestid böcekler ve kemik böcekleri daha sonra gelirler. Adli entomolojinin en etkili uygulamast, ölümden sonraki ilk aydır( 7,11$)$. 
Yürïyen ve uçan böceklere birkaç örnek $(8,9,10)$

Insan cesedi ve hayvan leşleri, ergißleşmiş sinekler içın proteinli bir besin kaynağı olduğu gibi, larvalar içinde besleyici bir ortamdır. Erginieşnilis sinekler, yumurtalarmı cesedin gölgeli ve katlı yerlerine birakırlar. En sık yumurtladıkları yer ise kan ve kusmukla bulaşmış saç aralarıdır. Yumuriadan çıkşs. sicak havada birkaç saat, normal şartlar altında $20-24$ saat, soğuk havada ise 1-2 gün sürer.
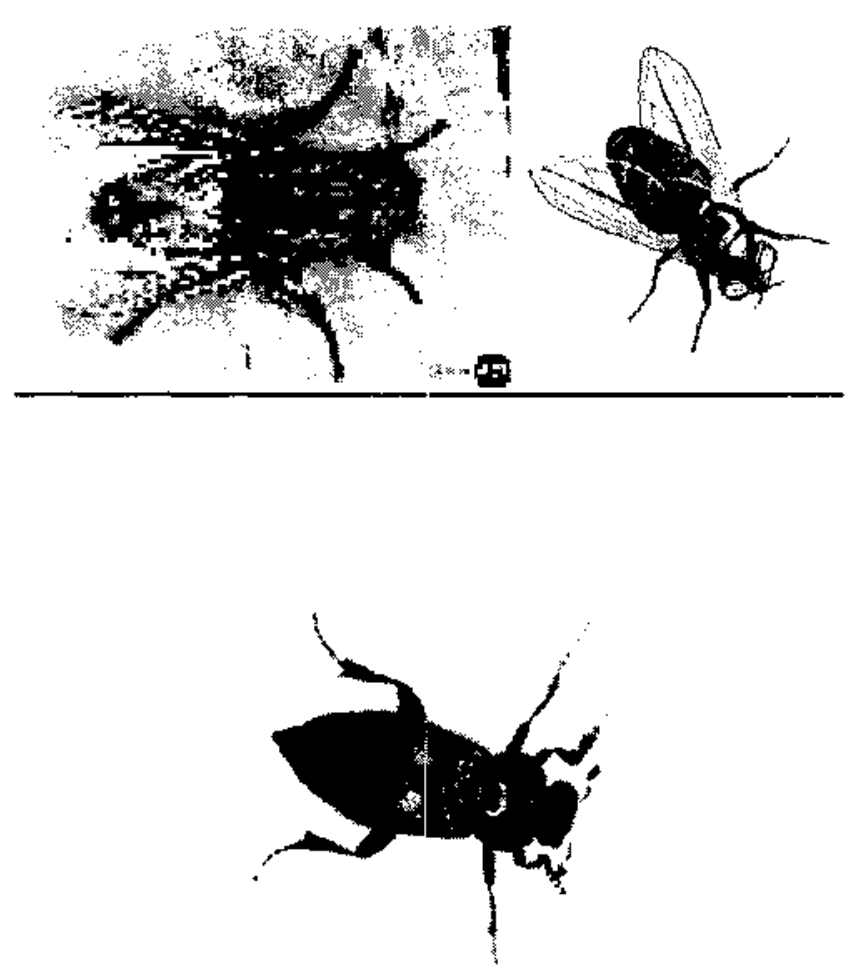


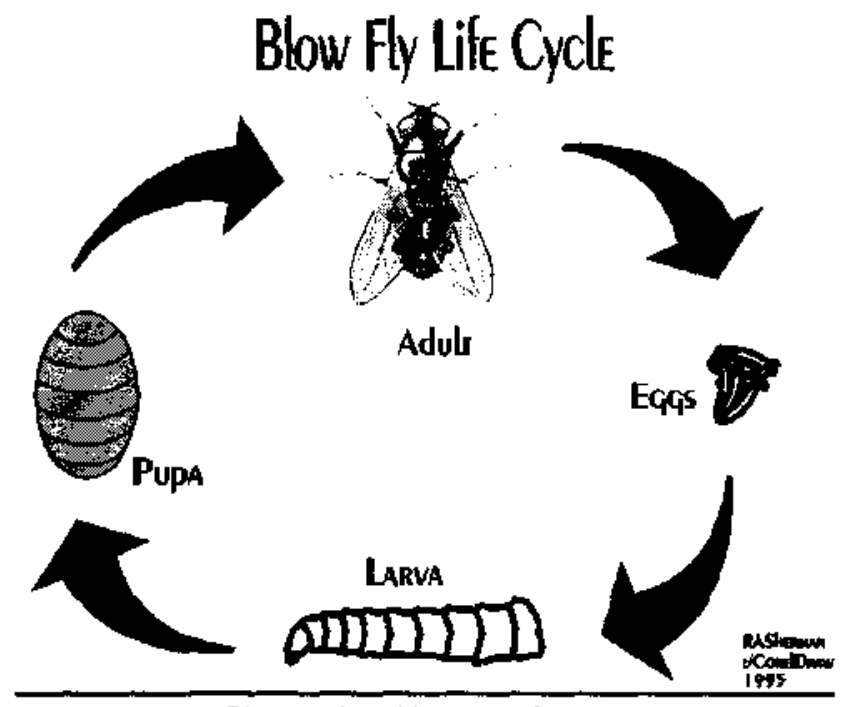

Bir uçan böceğin yaşam döngüsü

Sağlam ceset, sinekleri yumurtlamak için hemen çekmez ancak kusmuk, kan ya da açık yara varlığında yumurtlama birkaç dakika içinde gerçekleşir. Yara bulunmayan cesette yumurtlama, genellikle ölümden sonra 2. gün başlamakla birlikte sineklerin bol olduğu ortamlarda ya da cesedin güneş ışığına maruz kaldığı durumlarda yumurtlama daha erken olabilir. Saç. gözler, burun delikleri ve diğer doğal vücut boşlukları yumurtlama için en elverişli bölgelerdir.

Hastalarda ki açık yara ve irin oluşturan inflamatuar süreçler yumurtlamayı hızlandırmaktadır. Yumurtadan çıkan larvalar, önce nekrotik dokularla beslenerek yaşar, daha sonra taze dokuya geçer ve myasis hastalığını oluştururlar (7). Calliphora ve Lucilia larvaları ölü dokularla beslenirler, hatta ortama verdikleri allantoin ve amonyaktan dolayı yaraların iyileşmesi için yararlı đa olabilirler. I. Dünya savaşına kadar gaz yanıkları, osteomyelit gibi ağır yaraların tedavisinde bu larvalar kullanılmıştır. Antibiyotiklerin gelişmesiyle bu tedavi yöntemi bırakılmıştır (2). Adli uygulamada, sineklerin yumurta veya larvalarının yaraya ölümden önce mi yoksa ölüinden sonra mı bırakılmış olabileceğinin tespiti büyük önem taşımaktadır (7).

Bozulmuş, kokmuş, proteince zengin glda maddelerinin ve leşlerin uzerine yumurtalarını birakan Calliphoridae familyasına ait olan Calliphora erytrocephala, Auchmeromyia luteola ve Lucilia bufonivora larvalari buralarda geliştikten sonra pupa evresine girmek için toprağı delerler. İnsectlerin bu özelliğinin unutulmaması ve açı havada bulunan bir ceset olay yerinden alındığında cesedin alt kısmındaki ve etrafındaki toprağın 3-5 $\mathrm{cm}$ derinliğindeki bir alanının mutlaka taranması gereklidir. Ceset üzerinde 
hiç böcek olmaması, kişinin çok soğuk bir yerde öldüğünư, aşırı bir şekilde yandığını veya kapahı bir konteynerda kaldığını düşündürebilir $(4,9)$.

İnsect'lerin kriminal araştırmalarda kullanılmasının en temel nedeni, bir cesedi en kısa sürede tespit edip bulan canlı türlerinden biri olmaları ve çürümenin her evresinde var olmalarının yanı sıra bazı türlerin; orman, kıyı, tepe, şehir gibi spesifik yaşam ve iklim şartlarına özgi olmasıdır. Her böceğin yaşadığı ortam farklıdır. Belli böceklerin belli ortamlarda yaşamaları tanı koydurucudur. Suda, karada, ormanda yaşayan böceklerin kendi ortamlarından başka bir ortamda bulunmaları, cesedin bir yerden bir başka yere taşındı ı̆ı göstermesi açısından çok önemlidir. Otomobil, gemi. otobüs gibi araçlardaki cesetle böckkler başka yerlere taşınabilirler ve saptanan bu entomolojik bulgular ölenin yer değiştirmesi hakkında son derece yararlı bilgiler verirler. Olay yerinin, cesedin alt kısmının, etrafinın dikkatlice incelenmesi sırasında cesedin bulunduğu ortama, yumurtla bırakma, larva, pupa ve erişkin olma süreçlerine göre o ortamda o an için yada tamamen olmaması gereken böcek bu ortama bir şekilde taşımmışır. Bu bilgi bize ölümün gerçekleştiği yada gerçekleşmediği yer hakkında çok ciddi kanıtlar verecektir. Tüm bunları göz önüne alan, bir adli entomolog, cinayet mahalli, cinayetin açı veya kapalı bir alanda işlenip işlenmediği ve cesedin başka bir bölgeye nakledilip edilmediği hakkında fikir sahibi olabilir. $(4,11)$.

Cesedin yanından veya etrafından böceklerin toplanması, ayırımı, muayenesi ve tanımlanması adli entomolojinin işidir $(2,4)$.

Adli tıp uygulamasında ölüm zamanı tayini açısından çok çeşitli kriterler ve yöntemler kullanılır. Bu yöntemlerin hiçbiri ölüm sonrası zamanın belirlenmesinde her zaman tam gïvenilir sonuçlar vermez. Özellikle cesedin $\mathrm{d}_{1}$ ş ortamda kaldı̆̆ı, çürümenin başladığı ve ilerlediği durumlarda, entomolojik incelemelerin ölüm zamanının belirlenmesindeki önemi artar. Yapılan birçok çalışmada adli soruşturma ve otopsi bulguları ile karşılaştırıldığında, entomolojik araştırmaların giivenilir bir yöntem olarak kabul edilebileceğinin gösterilmesi, ülkemizde de entomolojik araştırmaların yapılması ve adli tıbba uygulanmasının gerekliligini ortaya koyar (4). 


\section{KAYNAKLAR}

1. Byrd. J.H., Castner, J. L., Forensic Entomology, The Utility of Arthropods in Legal Investigations, CRC Press, 2001, p.:2-3.

2. Demirsoy, A., Yaşamın Temel kuralları, Omurgasızlar/Böcekler, Entomoloji, Cilt: II, Kısım: II, Meteksan A.Ş. 5. Baskı, Ankara, 1997, s.:782

3. Gök, Ş., Adli Tup, Filiz Kitabevi, Istanbul, 1983, s.:22.

4. Hancı, H., Duman, E.Ç.,Adaletin gerçekleşmesinde böceklerin de büyük yeri var!, Cumhuriyet Bilim Teknik, 2000, Sayı 674, s.:18-20.

5. Kamay, B.T., Adli Tip, I. Cilt, A.Ü. Tip Fak. Yayınlan Sayı 34, Ankara, 1953, s.:120, 141-157.

6. Kolusayın, Ö., Koç, S., Adli Tıp, Ölüm, Istanbul Üniv.Cerrahpaşa Tip Fak. Yayınlarmdan, Istanbul,1999, Cilt 1.s.:127-128.

7. Savran, B., Koç, S., Çetin, Gürsel, Kolusayın, Ö., Adli Entomoloji, Adli Tıp Dergisi, Cilt:10, Sayı: 1 4, Istanbul, 1994, s.:143-152.

8. www.dpo.uab.edu/jwells/FBL.html (erişim tarihi:19.11.2001).

9. www .uio.no/mostarke/forens ent html (erişim tarihi: 17.11.2001).

10. www.ndsu nodak.edu/instruct/brewer/index.htm (erişim tarihi: 02.11.2001).

11.Carvalho, LML., Thyssen PJ., Linhares, AX., Palhares, FAB., A checklist of Arthropods Associated with Pig Carrion and Human Corpses in Southeastern Brazil, Memorias do Instituto Oswaldo Cruz On-line, Jan.-Feb., 2000, Vol:95(1), pp.:135-138, www.dbbm.fiocruz.br/wwwmem/951/3822.html (erişim tarihi: 18.11.2001). 